\title{
Personal Strengths and Health Related Quality of Life in Dementia Caregivers from Latin America
}

\author{
Stephen K. Trapp, ${ }^{1}$ Paul B. Perrin, ${ }^{1}$ Richa Aggarwal, ${ }^{2}$ \\ Silvina Victoria Peralta, ${ }^{3}$ Miriam E. Stolfi, ${ }^{3}$ Eliana Morelli, ${ }^{3}$ Leticia Aracely Peña Obeso, ${ }^{4}$ \\ and Juan Carlos Arango-Lasprilla ${ }^{5}$
}

\author{
${ }^{1}$ Department of Psychology, Virginia Commonwealth University, Richmond, VA, USA \\ ${ }^{2}$ Department of Psychology, Drexel University, Philadelphia, PA, USA \\ ${ }^{3}$ Instituto San Lucas, Santa Fe, Argentina \\ ${ }^{4}$ CETYS University, Mexicali, Mexico \\ ${ }^{5}$ IKERBASQUE, Basque Foundation for Science, University of Deusto, Bilbao, Spain
}

Correspondence should be addressed to Juan Carlos Arango-Lasprilla; jcarango@deusto.es

Received 28 September 2014; Revised 13 January 2015; Accepted 20 January 2015

Academic Editor: Laura Piccardi

Copyright (C) 2015 Stephen K. Trapp et al. This is an open access article distributed under the Creative Commons Attribution License, which permits unrestricted use, distribution, and reproduction in any medium, provided the original work is properly cited.

\begin{abstract}
The research literature has begun to demonstrate associations between personal strengths and enhanced psychosocial functioning of dementia caregivers, but these relationships have not been examined in the context of dementia caregivers in Latin America. The present study examined whether personal strengths, including resilience, optimism, and sense of coherence, were associated with mental and physical health related quality of life (HRQOL) in 130 dementia caregivers in Mexico and Argentina. Structural equation modeling found that the personal strengths collectively accounted for $58.4 \%$ of the variance in caregiver mental HRQOL, and resilience, sense of coherence, and optimism each had unique effects. In comparison, the personal strengths together accounted for $8.9 \%$ of the variance in caregiver physical HRQOL, and only sense of coherence yielded a unique effect. These results underscore the need to construct and disseminate empirically supported interventions based in part on important personal strengths, particularly sense of coherence, for this underrepresented group.
\end{abstract}

\section{Introduction}

Dementia is a progressive chronic illness that causes changes in the brain resulting in global cognitive and intellectual decline, memory deficits, and significant impairments in daily functioning [1]. An estimated 35.6 million people, primarily those 65 years and older, are currently living with dementia [2], with global rates expected to exceed 115.4 million by $2050[3,4]$. The global costs of dementia care in 2010 were $\$ 604$ million and will rise substantially in accordance with the increasing projected number of diagnoses [4]. The later stage dementia often requires inpatient care $[5,6]$, but it is common for an individual with dementia to require some degree of caregiving over the course of the disease. The majority of older individuals with dementia receive assistance from their spouse or adult children $[7,8]$. In the United States alone, 15 million informal caregivers (e.g., family members and friends) provide care for individuals with dementia, and over $50 \%$ of these are residential caregivers living in the same household as the patient [3]. Although caregiving is sometimes divided among several family members or friends, the majority of care is typically provided by one individual [9].

Caregiving for individuals with dementia can be particularly burdensome due to the myriad needs and symptoms associated with the condition [10]. Dementia often begins with mild memory problems, language difficulties, and impairments with activities of daily living [11]. Behavioral symptoms can include unintentional wandering, repetitive questioning, shadowing, aggressiveness, sleep disorders, and hoarding $[12,13]$. Many individuals with dementia also develop neuropsychiatric symptoms $[1,13,14]$ such as depression, verbal and physical agitation, and anxiety and in 
the later stages can develop more severe symptoms such as delusions, hallucinations, and disinhibition $[1,15,16]$. These symptoms often become so severe in the later stages that they result in hospitalization $[5,6]$.

Because of these symptoms, caregiving for an individual with dementia is often seen as more stressful than caregiving for other elderly populations with serious disabilities, such as physical impairments [17]. Research has identified associations between symptoms of dementia and reduced caregiver mental health, including anger, burden, anxiety, depression, guilt, and worry $[18,19]$. Physical health problems related to caregiving, such as decreased immune system functioning [20], hypertension [21], cardiovascular disease [22], and sleep problems [23] are also common. Social functioning problems include relationship challenges [24], greater family dysfunction [25], feelings of isolation, and inadequate social support [26].

Health-related quality of life (HRQOL) has been shown to be reduced in dementia caregivers [27-29]. HRQOL integrates physical health, psychological functioning, social relationships, personal beliefs, and perceptions of healthrelated events into a cumulative construct tapping an individual's overall well-being $[30,31]$. Research has begun to investigate HRQOL in dementia caregivers from Colombia [32]. When compared to a control group, it was found that dementia caregivers in Colombia scored significantly poorer on each subscale of the SF36, indicating notably lower overall HRQOL for these individuals.

Despite the reduced mental health and HRQOL shown in dementia caregivers, many also report a variety of positive experiences related to caregiving and exhibit little distress [33]. Resilience-effective coping and adaptation when faced with loss, hardship, or adversity [34] — has been identified as a protective factor against caregiver stress $[35,36]$. Similarly, optimism-a general positive outlook on life [37] - has been associated with improved dementia caregiver mental health $[9,38]$. Sense of coherence is an individual's orientation towards handling stress, namely, the degree to which an individual believes that he or she can comprehend, manage, and make meaning of a challenging life event [39]. SOC has been noted in dementia caregivers, namely, related to the level of caregiver burden experienced [40].

Overall, the extant literature suggests that personal strengths are associated with improved dementia caregiver psychosocial functioning. Yet, no research has investigated whether these protective factors are associated with caregiver mental and physical HRQOL, and by extension these potential associations have not been examined among dementia caregivers in Latin America. Considering that the estimated prevalence rates of dementia in Latin America match to those in developed countries [41], a need to examine dementia care in Latin America is clear. The purpose the current study was to examine whether resilience, optimism, and sense of coherence are associated with mental and physical HRQOL in dementia caregivers from Argentina and Mexico. It is hypothesized that these personal strengths will be positively associated with both mental and physical HRQOL.

\section{Method}

2.1. Participants. Participants for the present study were dementia caregivers from Argentina $(n=110)$ and Mexico ( $n=20)$. Participants were recruited from two sites: Centro de Enseñanza Técnica y Superior University in Baja California, Mexico, and Instituto de Neurosciencias de San Lucas in Rosario, Argentina. Caregivers were defined as individuals providing daily care for an individual diagnosed with dementia. Inclusion criteria were that caregivers had to be 18 years of age or older, identify as the primary caregiver of the person with dementia, have provided care for at least three months, be well-informed regarding the patient's medical and family history, and have no history of serious psychiatric or neurological disorders.

The majority of the caregiver sample $(77.7 \%)$ was female. Most of the participants were married $(76.9 \%) ; 12.3 \%$ were single; $4.6 \%$ divorced; $0.8 \%$ civil union; $0.8 \%$ separated; and $0.8 \%$ widowed. The majority of the caregivers were family caregivers, but nearly $5 \%$ of the sample included nonfamilial caregivers. Specifically, almost equal parts of the sample were the spouse $(43.8 \%)$ or child $(43.1 \%)$ of the individual with dementia, $7.7 \%$ aunt or uncle, $2.3 \%$ "other," $1.5 \%$ professional caregiver, $0.8 \%$ parent, and $0.8 \%$ friend. The mean age of caregivers was 56.84 years $(\mathrm{SD}=$ 13.18). Participants had provided care for an average of 46.94 months ( $S D=26.66)$, and the average weekly time spent caregiving was 68.48 hours $(\mathrm{SD}=30.64)$. Caregiver level of education included incomplete primary school $(1.5 \%)$, completed primary (14.6\%), incomplete baccalaureate $(3.1 \%)$, complete baccalaureate $(37.7 \%)$, incomplete technical school (1.5\%), complete technical school (3.8\%), incomplete university $(3.1 \%)$, complete university $(30.8 \%)$, and postgraduate (3.8\%). In regard to household income, $0.8 \%$ earned less than minimum wage, $50.7 \%$ one to three times minimum wage, $24.6 \%$ four to five times, and $23.8 \%$ more than five times minimum wage.

\subsection{Measures}

2.2.1. Short Form Health Survey (SF-36). A Spanish version of SF-36 [42] validated on a Colombian sample [43] was used to assess eight domains of overall HRQOL: physical functioning, social functioning, physical role-limitations, emotional role-limitations, general health, mental health, pain, and vitality. SF-36 subscale scores range from 0 to 100, with higher scores indicating greater perceived HRQOL. On the SF-36, HRQOL can be broken down into two general factors by calculating the means of mental HRQOL (e.g., vitality, social functioning, mental health, emotional role-limitations) and physical HRQOL (e.g., physical functioning, physical rolelimitations, pain, general health; [42]). The instrument has demonstrated adequate internal consistency, with Cronbach's alphas generally above 0.85 [44]. The SF-36 has been used extensively in Latin America with previous research on caregivers of individuals with neurological conditions such as multiple sclerosis [45], traumatic brain injury [46], and dementia [47]. 
2.2.2. Resilience Scale for Adults (RSA). The RSA [48, 49] was used to assess caregiver resilience. The scale is comprised of 36 items utilizing a seven-item Likert scale with five subscales that include personal competence, social competence, family coherence, social support, and personal structure. Each subscale demonstrated adequate internal reliability $(0.90,0.83$, $0.87,0.83$, and 0.67 , resp.) in the original validation [49]. Example items include "I believe in my own abilities" and "Believing in myself helps me to overcome difficult times."

2.2.3. Sense of Coherence Scale (SOC). The SOC [50], validated for Spanish speakers [51], was used to assess sense of coherence. The scale is comprised of 13 items utilizing a seven-point Likert scale and has a three-subscale structure including meaningfulness, comprehensibility, and manageability. Cronbach's alphas have ranged from 0.70 to 0.95 in 127 studies [52]. Example items included "Do you have the feeling that you really do not care about what is going on around you?" and "Do you have the feeling that you are in an unfamiliar situation and do not know what to do?"

2.2.4. Life Orientation Scale-Revised (LOT-R). The LOT-R [53] assessed caregiver dispositional optimism. The scale is comprised of 10 items utilizing a four-item Likert scale with one total score. The original instrument has demonstrated adequate internal consistency with Cronbach's alpha of .82 [53]. Example items included "In uncertain times, I usually expect the best" and "I do not get upset too easily."

2.3. Procedure. Participants at Centro de Enseñanza Técnica y Superior University in Baja California, Mexico, were recruited by word of mouth, flyers, and telephone contact utilizing a list of numbers generated from the Alzheimer's Foundation of Baja California. Although three caregiver participants were administered the measures on site at the Alzheimer's Foundation, $85 \%$ of the participants were administered the measures via telephone. Participants at Instituto de Neurociencias de San Lucas in Rosario, Argentina, were recruited during routine visits to the attending neurologist. Caregivers were administered the measures during the appointment. Informed consent was obtained from all participants, and the data were collected in accordance with Institutional Review Board Approval at each facility.

2.4. Statistical Analyses. Two multiple regression analyses were conducted to examine which caregiver personal strengths (e.g., resilience, sense of coherence, and optimism) were associated with two aspects of HRQOL (e.g., physical HRQOL, mental HRQOL). These regressions were computed using AMOS 16.0 [54] in order to derive latent variables when possible which tend to be more accurate construct estimates than manifest variables. Because the sample size in the current study ( $n=130$ ) was below the sample size of 200 recommended for conducting structural equation modeling in rehabilitation research [55], estimates of fit were not reported or interpreted, as they would likely be inaccurate. Instead, standardized beta weights for the independent variables and the amount of variance explained in the dependent variables were the primary focus.
In each regression, the three personal strengths were entered simultaneously as independent variables, and the dependent variable was either physical or mental HRQOL. The latent variables in the models included resilience (made up of the five subscales of the RSA), sense of coherence (made up of the three subscales of the SOC), mental HRQOL (made up of the SF-36 subscales of Vitality, Social Functioning, Mental Health, and Role Limitations-Emotional), and physical HRQOL (made up of the SF-36 subscales of Physical Functioning, Role Limitations-Physical, Pain, and General Health). Optimism was the only manifest independent variable (comprised of the LOT-R total score). A correlation matrix of all manifest indices of the primary constructs in the current study was then computed using SPSS 21.0.

\section{Results}

3.1. Descriptive Statistics. The means of the manifest variables for mental HRQOL were as follows: vitality $\mathrm{M}=55.15, \mathrm{SD}=$ 12.53 , range $=10.00-100.00$; social functioning $\mathrm{M}=78.65$, $\mathrm{SD}$ $=18.87$, range $=25.00-100.00$; role-emotional $\mathrm{M}=63.08, \mathrm{SD}$ $=44.75$, range $=00.00-100.00$; and mental health $\mathrm{M}=56.43$, $\mathrm{SD}=13.2$, range $=16.00-100.00$. The means of the manifest variables for physical HRQOL were as follows: general health $\mathrm{M}=72.50, \mathrm{SD}=21.28$, range $=15.00-100.00$; bodily pain $\mathrm{M}=88.17, \mathrm{SD}=18.06$, range $=22.50-100.00$; role-physical $\mathrm{M}=61.63, \mathrm{SD}=46.88$, range $=00.00-100.00$; and physical functioning $\mathrm{M}=88.15, \mathrm{SD}=19.25$, range $=00.00-100.00$.

The resilience variable means included personal competence $(\mathrm{M}=55.47, \mathrm{SD}=8.20$, range $=37.00-70.00)$, social competence $(\mathrm{M}=40.72, \mathrm{SD}=5.30$, range $=23.00-49.00)$, family coherence $(\mathrm{M}=39.15, \mathrm{SD}=7.21$, range $=21.00$ $49.00)$, social support $(M=48.41, S D=5.67$, range $=24.00-$ $56.00)$, and personal structure $(\mathrm{M}=24.24, \mathrm{SD}=2.78$, range $=$ 12.00-28.00). The means for the sense of coherence variable included meaningfulness $(\mathrm{M}=22.83, \mathrm{SD}=3.76$, range $=$ 7.00-28.00), comprehensibility $(\mathrm{M}=25.68, \mathrm{SD}=4.85$, range $=10.00-34.00)$, and manageability $(\mathrm{M}=20.61, \mathrm{SD}=4.22$, range $=8.00-28.00)$. The mean for optimism was $17.26(\mathrm{SD}=$ 2.96 ) with a range of $7.00-24.00$ and higher scores indicating greater dispositional optimism.

3.2. Regressions with Personal Strengths and HRQOL. In the first regression (Figure 1), the personal strengths collectively accounted for $58.4 \%$ of the variance in caregiver mental HRQOL. Resilience $(\beta=-.255, P<.039)$, sense of coherence $(\beta=.704, P<.001)$, and optimism $(\beta=.319, P<.002)$ were significantly and independently associated with caregiver mental HRQOL. In the second regression (Figure 2), the personal strengths together accounted for $8.9 \%$ of the variance in caregiver physical HRQOL. Sense of coherence $(\beta=.298$, $P<.028)$ was significantly and independently associated with caregiver physical HRQOL, while resilience $(\beta=-.125$, $P=.342)$ and optimism $(\beta=.097, P=.378)$ were not.

\subsection{Bivariate Correlations among Personal Strengths and} HRQOL. A bivariate correlation matrix was then created among all manifest indices of the primary constructs in the current study (Table 1). All personal strengths were 


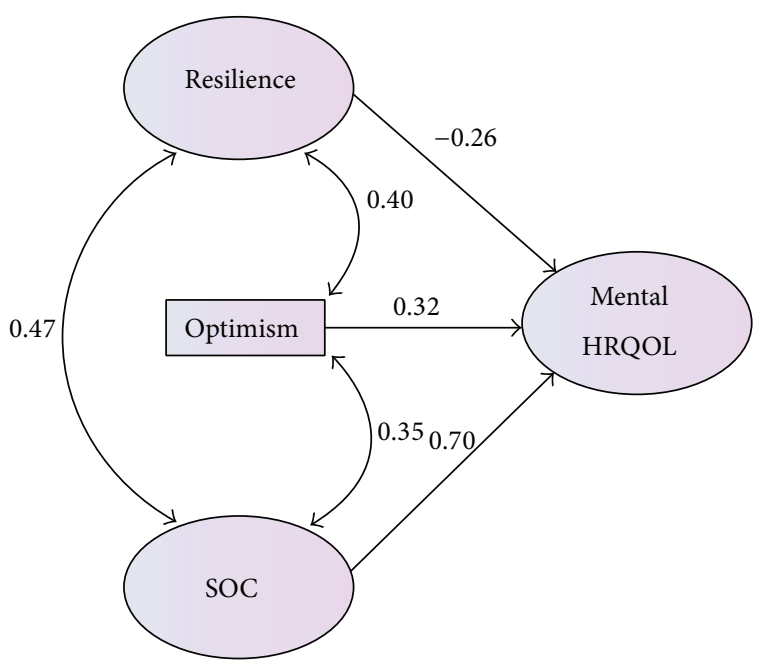

FIGURE 1: Note. SOC $=$ sense of coherence; HRQOL $=$ health related quality of life.

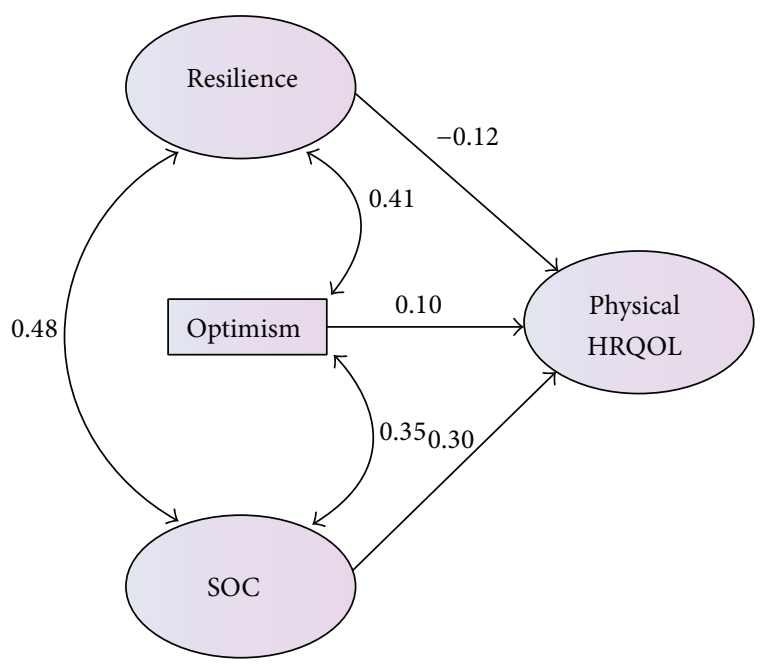

FIGURE 2: Note. $\mathrm{SOC}=$ sense of coherence; HRQOL $=$ health related quality of life.

significantly related to each other, and mental and physical HRQOL were highly correlated. All personal strengths were positively associated with mental HRQOL, but only sense of coherence was positively correlated with physical HRQOL.

\section{Discussion}

The extant literature has begun to demonstrate associations between personal strengths and enhanced psychosocial functioning of dementia caregivers [36], but these relationships have not been examined in the context of dementia caregivers in Latin America. To attend to this gap in the research, the present study examined whether resilience, optimism, and sense of coherence (SOC) were associated with mental and physical HRQOL in dementia caregivers in Mexico and Argentina. Bivariate correlations and multiple
TABLE 1: Correlations among personal strengths and HRQOL.

\begin{tabular}{|c|c|c|c|c|c|}
\hline & 1 & 2 & 3 & 4 & 5 \\
\hline (1) Physical HRQOL & - & - & - & - & - \\
\hline (2) Mental HRQOL & $.693^{* * *}$ & - & - & - & - \\
\hline (3) Resilience & .126 & $.224^{* *}$ & - & - & - \\
\hline (4) Sense of coherence & $.258^{* *}$ & $.499^{* * *}$ & $.411^{* * *}$ & - & - \\
\hline (5) Optimism & .116 & $.283^{* * *}$ & $.482^{* * *}$ & $.317^{* * *}$ & - \\
\hline
\end{tabular}

regressions generally supported the hypothesis that these personal strengths would be associated with caregiver HRQOL, although the effect was substantially stronger for mental HRQOL than physical HRQOL.

In the two multiple regressions, SOC was independently associated with both mental and physical HRQOL. According to Antonovsky's [56] salutogenic theory and empirical findings in a variety of samples focusing on the relationship between SOC and HRQOL [52], SOC may act as an internal resource augmenting control over one's life and health. Positive appraisals of the meaningfulness, comprehensibility, and manageability of dementia caregiving challenges in the current study may have acted as psychological resources to bolster healthy behaviors and increase positive affect, each related to greater mental and physical health $[57,58]$. Latino caregivers often derive meaning from caregiving [59], so it is not surprising that SOC was associated with both components of HRQOL. It could be interpreted that individuals who value caregiving may also make positive appraisals of the meaningfulness of challenging events and engage in healthy behaviors surrounding those events, thus maintaining their mental and physical HRQOL. Future treatments focusing on SOC and caregiving values may be efficacious in increasing HRQOL among Latin American caregivers.

The finding that dementia caregiver resilience was independently associated with mental HRQOL is in line with previous dementia caregiver studies conducted in the United States, which have demonstrated associations between resilience and increased mental health in dementia caregivers $[35,36,60]$. Resilience is considered to act as a protective factor by increasing the quality of caregiver coping and overall adaptation to difficulties related to caregiving [34]. It could be inferred that a similar pathway to better mental health occurs in dementia caregivers in Latin America. Among other personal strengths, future intervention research would benefit from focusing on dementia caregiver resilience in Latin America in order to augment caregiver coping and mental health.

The finding that optimism was independently associated with dementia caregiver mental HRQOL also conforms to previous findings on dementia caregivers in North America [61]. The positive expectancies caregivers place on coping options and subsequent outcomes are thought to increase caregivers' perceptions of available coping techniques [62, 63]. These positive expectancies and effects on mental health are likely also present for dementia caregivers in Latin America. Cognitive behavioral interventions that improve the optimism of dementia caregivers in this region may 
diversify the number of coping strategies they have available and improve their mental HRQOL.

Perhaps the most notable finding was that these personal strengths accounted for over six times the variance in mental HRQOL as physical HRQOL. Despite the evidence for salutary independent associations between resilience and optimism with mental HRQOL, these independent associations did not emerge with physical HRQOL. This finding generally conforms to that from previous research in other geriatric and rehabilitation populations showing that resilience [64] and optimism [65] are associated with mental HRQOL, but not with physical HRQOL. Caregiving for family members with a health condition is valued in Latino cultures [66], and increased informal care predisposes family members to a myriad of physical caregiving burdens [17]. It is possible that positive psychological resources do not protect against the direct physical responsibilities of caregiving (e.g., patient surveillance, physical care, and lack of sleep) as strongly as they do mental HRQOL.

The findings of the present study suggest that HRQOL in dementia caregivers may benefit from interventions focusing on the role of personal strengths. There is much evidence to suggest that interventions for dementia caregivers have positive psychosocial effects for caregivers and individuals with dementia [67, 68]. Effects for caregivers include increased overall mental health and greater caregiver skill competencies, while individuals with dementia have been found to benefit through increased mental health and delayed admission for inpatient services [69].

Considering the central role of SOC in caregiver HRQOL in the present study, interventions for dementia caregivers in Latin America may benefit from strengthening caregivers' positive appraisals of the meaningfulness, comprehensibility, and manageability of caregiving activities. Previous dementia caregiver research in developed nations has demonstrated associations between dementia caregivers' HRQOL and SOC $[40,70]$, and a base of dementia caregiver research in Latin America has demonstrated associations between HRQOL and other important caregiving outcomes such as mental health [47].

A coping skills training program is a common component of interventions to reduce caregiver burden [68]. A variety of intervention studies have shown positive changes in SOC in diverse patient populations after meaning-focused treatments [71-73]. Clinicians may support dementia caregivers by examining caregivers' appraisals of the meaningfulness, comprehensibility, and manageability of challenging caregiving experiences and by reinforcing the importance of the psychosocial facets in caregivers' overall well-being. Developing treatments around these areas may have positive outcomes for the overall HRQOL of dementia caregivers in Latin America.

4.1. Limitations and Future Directions. Although the findings have implications for clinical practice in Latin America, the present study has several limitations and, as a result, directions for future research. The cross-sectional design of the study provides baseline evidence to examine the potential influence of personal strengths on caregiver HRQOL but does not allow for an examination of how these factors may influence caregiver HRQOL over time. Future studies would benefit from collecting longitudinal data in order to better demonstrate how caregiver strengths and HRQOL change over the course of caregiving. Second, specific clinical characteristics of the participants with dementia could not be gathered within the scope of the study. Clinical expressions, such as behavioral and cognitive functioning, of the participants with dementia could have provided greater information regarding caregiver stress. Specifically, the clinical features may have demonstrated moderating relations in which type and level of functioning may have held differing associations with caregiver stress. Future studies examining this topic would benefit from gathering a wider range of clinical data of the participants with dementia. Third, the study would have benefitted from examining the manner in which the personal strengths influence caregiver HRQOL. A larger sample would have allowed for more sophisticated analyses to examine possible meditational pathways from which the personal strengths and caregiver HRQOL may interact. Experimental designs would also provide evidence for causality in the relationship between personal strengths and caregiver HRQOL. Fourth, the study benefited from samples in two areas of Latin America; however, this cannot be considered representative of dementia caregivers in other regions of Latin America. Sampling from more diverse settings would provide a more accurate picture of findings from this study.

Despite these limitations, the results of the present study are notable due to the dearth of research on the personal strengths and HRQOL of dementia caregivers in Latin America. The results supported the hypothesis that personal strengths would be associated with mental and physical HRQOL in dementia caregivers from Latin America. These results underscore the need to construct and disseminate empirically supported interventions based in part on important personal strengths, such as meaning-focused treatments pertaining to SOC [71-73], for this underrepresented group. Improving the HRQOL of caregivers is expected to have a variety of positive effects, not only for the caregiver, but also for the quality of care they provide to individuals with dementia.

\section{Conflict of Interests}

The authors declare that there is no conflict of interests regarding the publication of this paper.

\section{References}

[1] M. A. Nowrangi, V. Rao, and C. G. Lyketsos, "Epidemiology, assessment, and treatment of dementia," Psychiatric Clinics of North America, vol. 34, no. 2, pp. 275-294, 2011.

[2] M. Prince and J. Jackson, World Alzheimer Report 2009, Alzheimer's Disease International, 2009.

[3] W. Thies and L. Bleiler, "2011 Alzheimer's disease facts and figures," Alzheimer's \& Dementia, vol. 7, no. 2, pp. 208-244, 2011.

[4] World Health Organization, Dementia: A Public Health Priority, World Health Organization, 2012. 
[5] G. M. Savva, J. Zaccai, F. E. Matthews, J. E. Davidson, I. McKeith, and C. Brayne, "Prevalence, correlates and course of behavioural and psychological symptoms of dementia in the population," The British Journal of Psychiatry, vol. 194, no. 3, pp. 212-219, 2009.

[6] I.-S. Shin, M. Carter, D. Masterman, L. Fairbanks, and J. L. Cummings, "Neuropsychiatric symptoms and quality of life in Alzheimer disease," The American Journal of Geriatric Psychiatry, vol. 13, no. 6, pp. 469-474, 2005.

[7] R. J. Montgomery, "Gender differences in patterns of childparent caregiving relationships," in Gender, Families, and Elder Care, J. W. Dwyer and R. T. Coward, Eds., pp. 65-83, 1992.

[8] R. E. Schulz, Handbook on Dementia Caregiving: EvidenceBased Interventions for Family Caregivers, Springer, 2000.

[9] R. Schulz and L. M. Martire, "Family caregiving of persons with dementia: prevalence, health effects, and support strategies," The American Journal of Geriatric Psychiatry, vol. 12, no. 3, pp. 240-249, 2004.

[10] R. F. Allegri, D. Sarasola, C. M. Serrano et al., "Neuropsychiatric symptoms as a predictor of caregiver burden in Alzheimer's disease," Neuropsychiatric Disease and Treatment, vol. 2, no. 1, pp. 105-110, 2006.

[11] W. A. Kukull and J. D. Bowen, "Dementia epidemiology," Medical Clinics of North America, vol. 86, no. 3, pp. 573-590, 2002.

[12] L. N. Gitlin, L. Winter, M. P. Dennis, N. Hodgson, and W. W. Hauck, "Targeting and managing behavioral symptoms in individuals with dementia: a randomized trial of a nonpharmacological intervention," Journal of the American Geriatrics Society, vol. 58, no. 8, pp. 1465-1474, 2010.

[13] C. G. Lyketsos, M. C. Carrillo, J. M. Ryan et al., "Neuropsychiatric symptoms in Alzheimer's disease," Alzheimer's and Dementia, vol. 7, no. 5, pp. 532-539, 2011.

[14] C. G. Lyketsos, O. Lopez, B. Jones, A. L. Fitzpatrick, J. Breitner, and S. Dekosky, "Prevalence of neuropsychiatric symptoms in dementia and mild cognitive impairment: results from the Cardiovascular Health Study," The Journal of the American Medical Association, vol. 288, no. 12, pp. 1475-1483, 2002.

[15] Y. E. Geda, R. O. Roberts, D. S. Knopman et al., "Prevalence of neuropsychiatric symptoms in mild cognitive impairment and normal cognitive aging: population-based study," Archives of General Psychiatry, vol. 65, no. 10, pp. 1193-1198, 2008.

[16] F. E. Taragano, R. F. Allegri, H. Krupitzki et al., "Mild behavioral impairment and risk of dementia: a prospective cohort study of 358 patients," The Journal of Clinical Psychiatry, vol. 70, no. 4, pp. 584-592, 2009.

[17] M. Pinquart and S. Sörensen, "Differences between caregivers and noncaregivers in psychological health and physical health: a meta-analysis," Psychology and Aging, vol. 18, no. 2, pp. 250267, 2003.

[18] W. Black and O. P. Almeida, "A systematic review of the association between the behavioral and psychological symptoms of dementia and burden of care," International Psychogeriatrics, vol. 16, no. 3, pp. 295-315, 2004.

[19] R. Mahoney, C. Regan, C. Katona, and G. Livingston, "Anxiety and depression in family caregivers of people with alzheimer disease: the laser-ad study," The American Journal of Geriatric Psychiatry, vol. 13, no. 9, pp. 795-801, 2005.

[20] J. K. Kiecolt-Glaser, P. T. Marucha, W. B. Malarkey, A. M. Mercado, and R. Glaser, "Slowing of wound healing by psychological stress,” The Lancet, vol. 346, no. 8984, pp. 1194-1196, 1995.
[21] W. S. Shaw, T. L. Patterson, M. G. Ziegler, J. E. Dimsdale, S. J. Semple, and I. Grant, "Accelerated risk of hypertensive blood pressure recordings among Alzheimer caregivers," Journal of Psychosomatic Research, vol. 46, no. 3, pp. 215-227, 1999.

[22] B. T. Mausbach, T. L. Patterson, Y. G. Rabinowitz, I. Grant, and R. Schulz, "Depression and distress predict time to cardiovascular disease in dementia caregivers," Health Psychology, vol. 26, no. 5, pp. 539-544, 2007.

[23] C. Simpson and P. Carter, "Dementia behavioural and psychiatric symptoms: effect on caregiver's sleep," Journal of Clinical Nursing, vol. 22, no. 21-22, pp. 3042-3052, 2013.

[24] L. W. Morris, R. G. Morris, and P. G. Britton, “The relationship between marital intimacy, perceived strain and depression in spouse caregivers of dementia sufferers," British Journal of Medical Psychology, vol. 61, no. 3, pp. 231-236, 1988.

[25] G. Tremont, J. D. Davis, and D. S. Bishop, "Unique contribution of family functioning in caregivers of patients with mild to moderate dementia," Dementia and Geriatric Cognitive Disorders, vol. 21, no. 3, pp. 170-174, 2006.

[26] P. Stoltz, G. Udén, and A. Willman, "Support for family carers who care for an elderly person at home-a systematic literature review," Scandinavian Journal of Caring Sciences, vol. 18, no. 2, pp. 111-119, 2004.

[27] J. M. Argimon, E. Limon, J. Vila, and C. Cabezas, "Healthrelated quality-of-life of care-givers as a predictor of nursinghome placement of patients with dementia," Alzheimer Disease \& Associated Disorders, vol. 19, no. 1, pp. 41-44, 2005.

[28] N. Gusi, J. Prieto, M. Madruga, J. M. Garcia, and J. L. GonzalezGuerrero, "Health-related quality of life and fitness of the caregiver of patient with dementia," Medicine \& Science in Sports \& Exercise, vol. 41, no. 6, pp. 1182-1187, 2009.

[29] J. S. Markowitz, E. M. Gutterman, K. Sadik, and G. Papadopoulos, "Health-related quality of life for caregivers of patients with Alzheimer disease," Alzheimer Disease \& Associated Disorders, vol. 17, no. 4, pp. 209-214, 2003.

[30] P. V. Rabins and J. D. Kasper, "Measuring quality of life in dementia: conceptual and practical issues," Alzheimer Disease and Associated Disorders, vol. 11, no. 6, pp. 100-104, 1997.

[31] P. Thomas, F. Lalloué, P.-M. Preux et al., "Dementia patients caregivers quality of life: the PIXEL study," International Journal of Geriatric Psychiatry, vol. 21, no. 1, pp. 50-56, 2006.

[32] J. C. Arango-Lasprilla, T. Lehan, A. Drew, A. Moreno, and M. Lemos, "Health-related quality of life in caregivers of individuals with dementia from Colombia," The American Journal of Alzheimer's Disease and other Dementias, vol. 25, no. 7, pp. 556561, 2010.

[33] B. J. Kramer, "Differential predictors of strain and gain among husbands caring for wives with dementia," The Gerontologist, vol. 37, no. 2, pp. 239-249, 1997.

[34] M. M. Tugade and B. L. Fredrickson, "Resilient individuals use positive emotions to bounce back from negative emotional experiences," Journal of Personality and Social Psychology, vol. 86, no. 2, pp. 320-333, 2004.

[35] J. Garity, "Caring for a family member with Alzheimer's disease: coping with caregiver burden post-nursing home placement," Journal of Gerontological Nursing, vol. 32, no. 6, pp. 39-48, 2006.

[36] S. E. Wilks and B. Croom, "Perceived stress and resilience in Alzheimer's disease caregivers: testing moderation and mediation models of social support," Aging and Mental Health, vol. 12, no. 3, pp. 357-365, 2008. 
[37] M. F. Scheier and C. S. Carver, "Optimism, coping, and health: assessment and implications of generalized outcome expectancies," Health Psychology, vol. 4, no. 3, pp. 219-247, 1985.

[38] W. E. Haley, D. L. Roth, M. I. Coleton et al., "Appraisal, coping, and social support as mediators of well-being in black and white family caregivers of patients with Alzheimer's disease," Journal of Consulting and Clinical Psychology, vol. 64, no. 1, pp. 121-129, 1996.

[39] A. Antonovsky, "The structure and properties of the sense of coherence scale," Social Science \& Medicine, vol. 36, no. 6, pp. 725-733, 1993.

[40] S. Andrén and S. Elmståhl, “The relationship between caregiver burden, caregivers' perceived health and their sense of coherence in caring for elders with dementia," Journal of Clinical Nursing, vol. 17, no. 6, pp. 790-799, 2008.

[41] R. Nitrini, C. M. C. Bottino, C. Albala et al., "Prevalence of dementia in Latin America: a collaborative study of populationbased cohorts," International Psychogeriatrics, vol. 21, no. 4, pp. 622-630, 2009.

[42] J. E. Ware, K. K. Snow, M. Kosinski, and B. Gandek, SF-36 Health Survey: Manual and Interpretation Guide, Quality Metric, 2000.

[43] L. E. Lugo, H. I. García, and C. Gómez, "Confiabilidad del cuestionario de calidad de vida en salud SF-36 en Medellín, Colombia," Revista Facultad Nacional de Salud Pública, vol. 24, no. 2, pp. 37-50, 2006.

[44] J. E. Brazier, R. Harper, N. M. B. Jones et al., "Validating the SF-36 health survey questionnaire: new outcome measure for primary care," British Medical Journal, vol. 305, no. 6846, pp. 160-164, 1992.

[45] M. Mickens, P. B. Perrin, A. Aguayo, M. A. Macias, and J. C. Arango-Lasprilla, "Comparing health-related quality of life and psychological well-being between Mexican MS caregivers and controls," Journal of Latina/o Psychology, vol. 1, no. 4, pp. 195203, 2013

[46] S. L. Gulin, P. B. Perrin, L. F. Stevens et al., "Health-related quality of life and mental health outcomes in Mexican TBI caregivers," Families, Systems \& Health, vol. 32, no. 1, pp. 53-66, 2014.

[47] P. B. Perrin, M. Morgan, E. Aretouli et al., "Connecting healthrelated quality of life and mental health in dementia caregivers from Colombia, South America," Journal of Alzheimer's Disease, vol. 39, no. 3, pp. 499-509, 2014.

[48] O. Hjemdal, O. Friborg, M. Martinussen, and J. H. Rosenvinge, "Preliminary results from the development and validation of a Norwegian scale for measuring adult resilience," Journal of the Norwegian Psychological Association, vol. 38, no. 4, pp. 310-317, 2001.

[49] O. Friborg, O. Hjemdal, J. H. Rosenvinge, and M. Martinussen, "A new rating scale for adult resilience: what are the central protective resources behind healthy adjustment?" International Journal of Methods in Psychiatric Research, vol. 12, no. 2, pp. 6576, 2003.

[50] A. Antonovsky, The Sense of Coherence Scale, Ben-Gurion University, Beersheba, Israel, 1985.

[51] J. Virués-Ortega, P. Martínez-Martín, J. L. del Barrio et al., "Cross-cultural validation of Antonovsky's Sense of Coherence Scale (OLQ-13) in Spanish elders aged 70 years or more," Medicina Clínica, vol. 128, no. 13, pp. 486-492, 2007.

[52] M. Eriksson and B. Lindström, "Validity of Antonovsky's sense of coherence scale: a systematic review," Journal of Epidemiology and Community Health, vol. 59, no. 6, pp. 460-466, 2005.
[53] M. F. Scheier, C. S. Carver, and M. W. Bridges, "Distinguishing optimism from neuroticism (and trait anxiety, self-mastery, and self-esteem): a reevaluation of the life orientation test," Journal of Personality and Social Psychology, vol. 67, no. 6, pp. 1063-1078, 1994.

[54] J. Arbuckle, AMOS 16.0 User's Guide, SPSS, Chicago, Ill, USA, 2007.

[55] R. Weston, P. A. Gore Jr., F. Chan, and D. Catalano, "An introduction to using structural equation models in rehabilitation psychology," Rehabilitation Psychology, vol. 53, no. 3, pp. 340$356,2008$.

[56] A. Antonovsky, "A call for a new question-salutogenesis- and a proposed answer-the sense of coherence," Journal of Preventive Psychiatry, vol. 2, no. 1, pp. 1-13, 1984.

[57] P. Salovey, A. J. Rothman, J. B. Detweiler, and W. T. Steward, "Emotional states and physical health," American Psychologist, vol. 55, no. 1, pp. 110-121, 2000.

[58] M. E. P. Seligman, "Positive health," Applied Psychology, vol. 57, no. 1, pp. 3-18, 2008.

[59] K. T. Lucke, H. Martinez, T. B. Mendez, and L. C. ArévaloFlechas, "Resolving to go forward: the experience of Latino/Hispanic family caregivers," Qualitative Health Research, vol. 23, no. 2, pp. 218-230, 2013.

[60] J. Garity, "Stress, learning style, resilience factors, and ways of coping in Alzheimer family caregivers," American Journal of Alzheimer's Disease and other Dementias, vol. 12, no. 4, pp. 171178, 1997.

[61] B. H. Gottlieb and J. A. Rooney, "Coping effectiveness: determinants and relevance to the mental health and affect of family caregivers of persons with dementia," Aging and Mental Health, vol. 8, no. 4, pp. 364-373, 2004.

[62] C. S. Carver, M. F. Scheier, and J. K. Weintraub, "Assessing coping strategies: a theoretically based approach," Journal of Personality and Social Psychology, vol. 56, no. 2, pp. 267-283, 1989.

[63] C. S. Carver, S. M. Spencer, and M. F. Scheier, "Optimism, motivation, and mental health," in Encyclopedia of Mental Health, vol. 3, pp. 41-52, Academic Press, San Diego, Calif, USA, 1998.

[64] B. Nygren, L. Aléx, E. Jonsén, Y. Gustafson, A. Norberg, and B. Lundman, "Resilience, sense of coherence, purpose in life and self-transcendence in relation to perceived physical and mental health among the oldest old," Aging and Mental Health, vol. 9, no. 4, pp. 354-362, 2005.

[65] C. F. Emery, D. J. Frid, T. O. Engebretson et al., "Gender differences in quality of life among cardiac patients," Psychosomatic Medicine, vol. 66, no. 2, pp. 190-197, 2004.

[66] S. R. Neary and D. F. Mahoney, "Dementia caregiving: the experiences of Hispanic/Latino caregivers," Journal of Transcultural Nursing, vol. 16, no. 2, pp. 163-170, 2005.

[67] I. Smits, B. Soenens, M. Vansteenkiste, K. Luyckx, and L. Goossens, "Why do adolescents gather information or stick to parental norms? Examining autonomous and controlled motives behind adolescents' identity style," Journal of Youth and Adolescence, vol. 39, no. 11, pp. 1343-1356, 2010.

[68] N. Van't Leven, A. E. J. C. Prick, J. G. Groenewoud, P. D. D. M. Roelofs, J. De Lange, and A. M. Pot, "Dyadic interventions for community-dwelling people with dementia and their family caregivers: a systematic review," International Psychogeriatrics, vol. 25, no. 10, pp. 1581-1603, 2013. 
[69] C. H. M. Smits, J. de Lange, R.-M. Dröes, F. Meiland, M. Vernooij-Dassen, and A. M. Pot, "Effects of combined intervention programmes for people with dementia living at home and their caregivers: a systematic review," International Journal of Geriatric Psychiatry, vol. 22, no. 12, pp. 1181-1193, 2007.

[70] T. H. Välimäki, K. M. Vehviläinen-Julkunen, A.-M. K. Pietilä, and T. A. Pirttilä, "Caregiver depression is associated with a low sense of coherence and health-related quality of life," Aging and Mental Health, vol. 13, no. 6, pp. 799-807, 2009.

[71] E. Langeland, T. Riise, B. R. Hanestad, M. W. Nortvedt, K. Kristoffersen, and A. K. Wahl, "The effect of salutogenic treatment principles on coping with mental health problems. A randomised controlled trial," Patient Education and Counseling, vol. 62, no. 2, pp. 212-219, 2006.

[72] E. Langeland, A. K. Wahl, K. Kristoffersen, and B. R. Hanestad, "Promoting coping: salutogenesis among people with mental health problems," Issues in Mental Health Nursing, vol. 28, no. 3, pp. 275-295, 2007.

[73] M. Sack, H. Künsebeck, and F. Lamprecht, "Sense of coherence and psychosomatic treatment outcome. An empirical study of salutogenesis," Psychotherapie, Psychosomatik, Medizinische Psychologie, vol. 47, no. 5, pp. 149-155, 1997. 


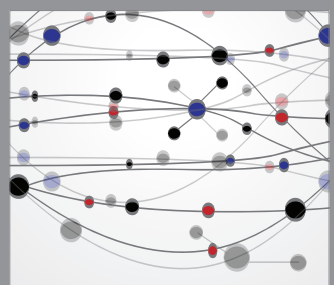

The Scientific World Journal
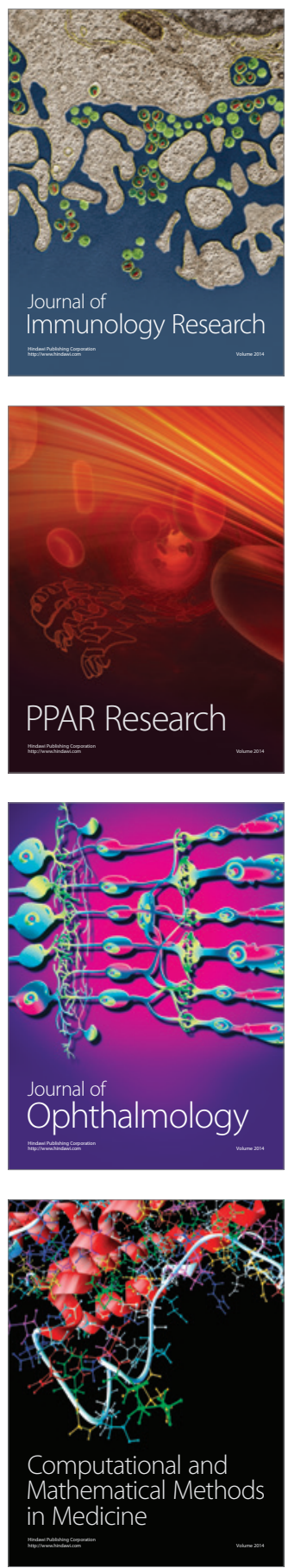

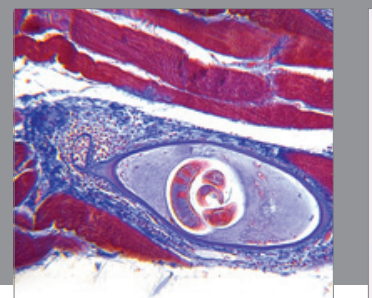

Gastroenterology

Research and Practice
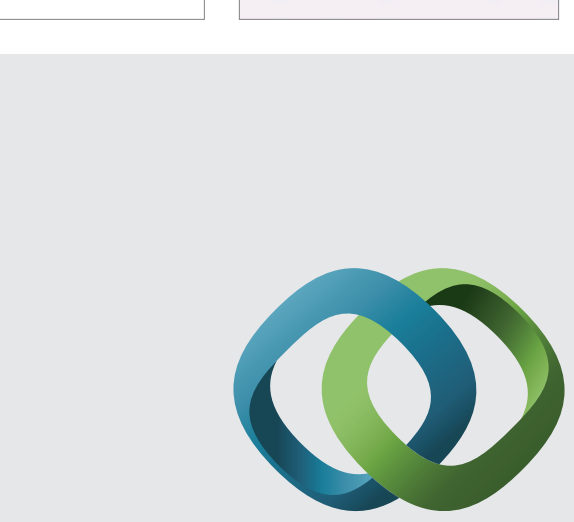

\section{Hindawi}

Submit your manuscripts at

http://www.hindawi.com
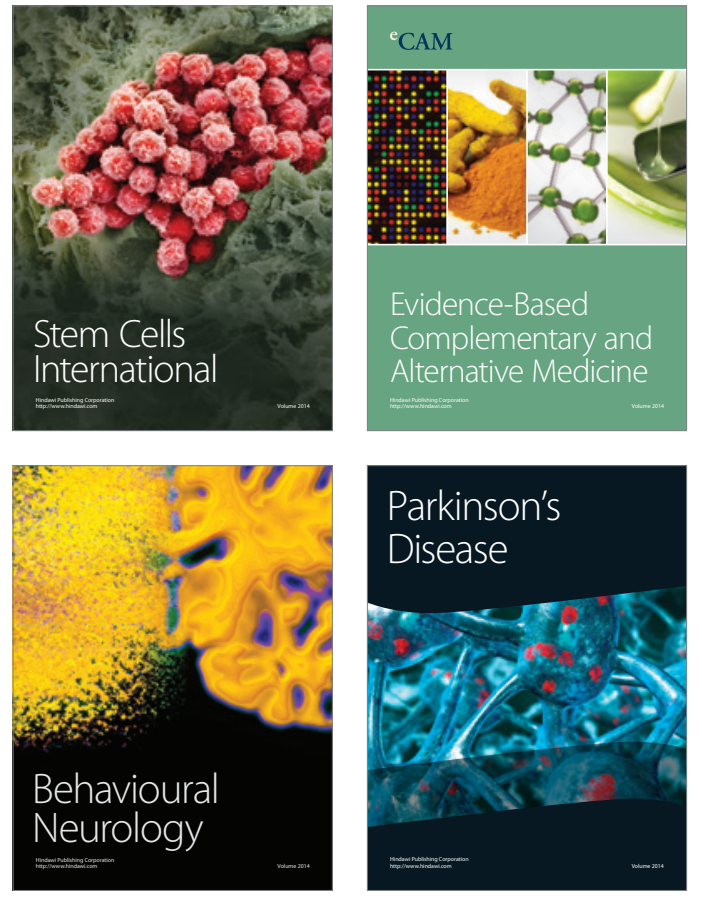
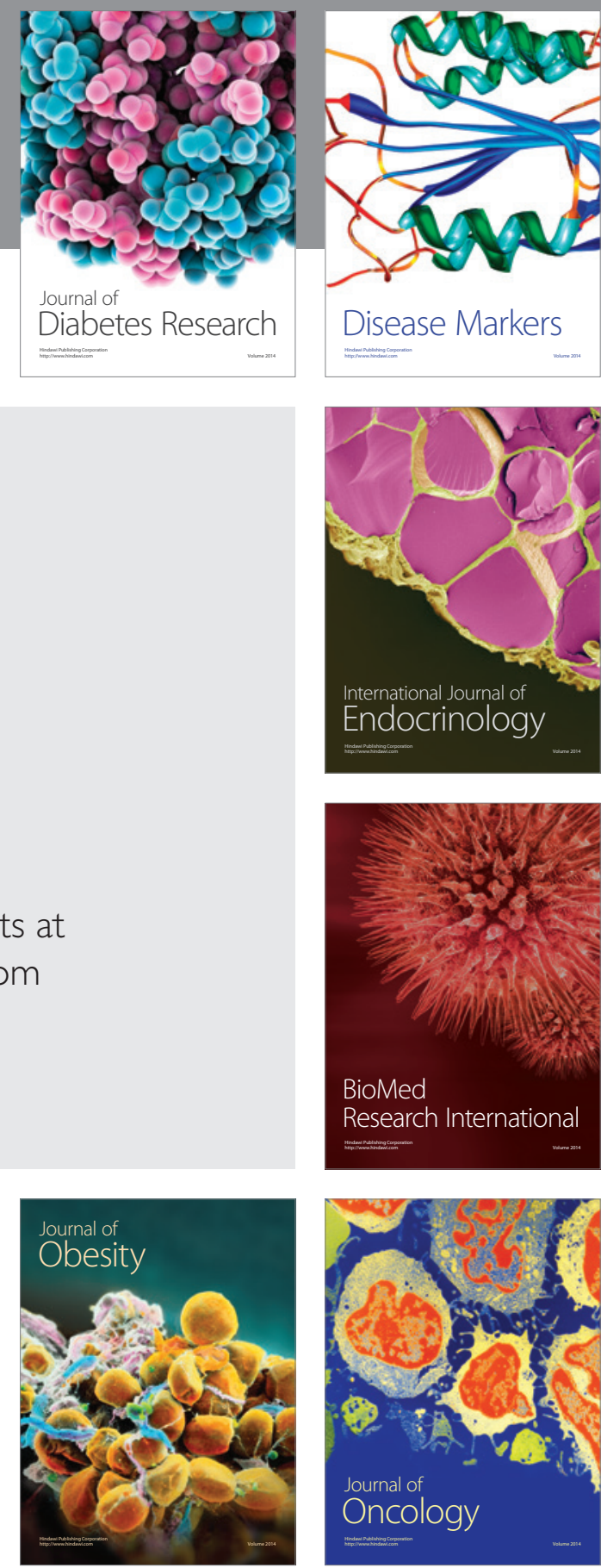

Disease Markers
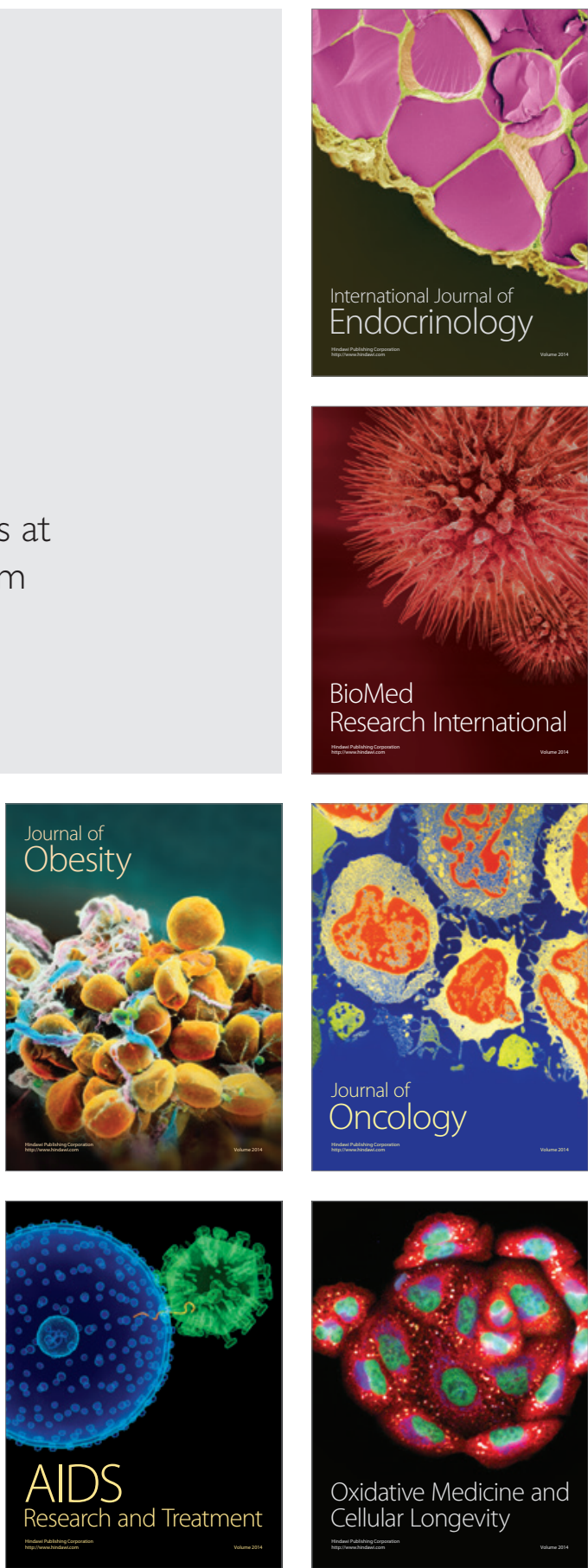